\title{
Attenuation of decameter sky noise during x-ray solar flares in 2013-2017 based on the observations at midlatitude radars
}

\author{
O.I.Berngardt \\ J.M.Ruohoniemi \\ N.Nishitani \\ S.G.Shepherd \\ W.Bristow \\ E.S.Miller
}

in

March 6, 2022

\begin{abstract}
Based on a joint analysis of the data from 10 midlatitude decameter radars the effects are investigated during $80 \mathrm{x}$-ray flares in the period 2013-2017. For the investigation nine mid-latitude SuperDARN radars of the northern hemisphere (Adak Island West and East radars, Blackstone radar, Christmas Valley East and West radars, Fort Hays East and West radars, Hokaido East radar and Wallops radar) and Ekaterinburg coherent decameter radar of ISTP SB RAS are used. All the radars work in the same $8-20 \mathrm{MHz}$ frequency band and have similar hardware and software. During the analysis the temporal dynamics of noise from each of the radar direction and for each flare is investigated separately. As a result, on the basis of about 13000 daily measurements we found a strong anticorrelation between noise power and x-ray flare intensity, that allows to use shortwave sky noise to diagnose the ionospheric effects of x-ray solar flares. It is shown that in $88.3 \%$ of cases an attenuation of daytime decameter radio noise is observed during solar flare, correlating with the temporal dynamics of the solar flare. The intensity of decameter noise anticorrelates well (the Pearson correlation coefficient better than -0.5) with the shape of the X-ray flare in the daytime (for solar elevation angle $>0$ ) in $33 \%$ of cases, the average Pearson correlation over the daytime is about -0.34 . Median regression coefficient between GOES 0.1-0.8nm x-ray intensity and daytime sky-noise attenuation is about $-4.4 \cdot 10^{4}\left[\mathrm{~dB} \cdot \mathrm{m}^{2} / W t\right]$. Thus, it has been shown that measurements of the decameter sky noise level at midlatitude decameter radars can be used to study the ionospheric absorption of high-frequency waves in the lower ionosphere during x-ray solar flares. This can be explained by the assumption that the most part of decameter sky noise detected by the radars can be interpreted as produced by ground sources at distances of the first propagation hop $(\sim 3000 \mathrm{~km})$.
\end{abstract}




\section{Introduction and motivation}

The widely known impact of solar flares to the Earth's ionosphere is the increase of the electron density due to additional ionization. This increase of the electron density in the lower ionosphere (in particular, at the D-layer heights) often leads to the increase of absorption of HF and VHF radio waves [29, 19]. Effect well known as Radio Blackout and widely studied at high latitudes by riometers [23, 22, 20, 19, 5. The absorption can be described by different models [15, 27, and most of them includes the following mechanisms: X-ray induced absorption (uses 0.1-0.8nm x-ray GOES data as proxi) and solar energetic particles induced absorption (uses integral proton fluxes above two energy levels - 5.2MeV and $2.2 \mathrm{MeV}$ ) [30, 14. At mid-latitudes this effect is weaker [19], and riometers are used relatively rarely. However, variations of the HF radio waves absorption at long radio paths including midlatitude ones during disturbed conditions are present, intensively investigated [25, 8, 17, 16, 34, 6, 28, 7. and estimated by the different prediction services (for example by NOAA at http://www.swpc.noaa.gov/products/3-day-forecast).

So making monitoring systems for high-frequency absorption effects at midlatitudes looks an important task, that stimulates extend of absorbtion observations to mid-latitudes [27.

Decameter radars with a narrow antenna pattern are widely used for the ionospheric studies, at mid- and high latitudes [18, 12, 1, 21, 33, 26, 3]. The widest network of such radars is the international network of coherent decameter radars SuperDARN (Super Dual Auroral Radar Network). Most of these radars are located near the polar caps [18, 12]. The recent expansion of the network to midlatitudes [1, 21, 26] makes it possible to use their equipment to diagnose the mid-latitude effects of solar flares.

Investigations of the effects of solar flares based on the data from decameter radars was carried out repeatedly [34, 32. The main and well known effect is the strong absorption of the propagating signal during the flare. During powerful (for example $\mathrm{X}$ and sometimes during $\mathrm{M}$ ) flares the absorption is so strong that it does not allow us to study in detail the dynamics of ionospheric ionization during a solar flare. During such flares we can only detect the presence or absence of a signal. By studies of Doppler velocity of the radar echoes and their range dependence during flares, estimates of the electron density change rate in the lower ionosphere can be made 34 .

The use of external sources of radiowaves can be used also for diagnosis 13, 32, but it seems not providing a good (world-wide) spatial coverage, and requires the use of permanent sources of radio emission for the organization of world-wide monitoring network. Sometimes it is not convenient.

Studies of noise level during solar flares have been conducted for a long time. The main effect during solar flares is increase of the noise level at almost all radiowave frequencies, that are produced by Sun [31, 11, 10. This is caused by the fact that radio frequencies below the gyrofrequency $f_{H}$ (of the order of $1 \mathrm{MHz}$ ) can propagate from the space to the Earth's surface by extraordinary mode. Very high frequency waves with frequencies above $30 \mathrm{MHz}$ are also slightly 
distorted by the ionosphere and can reach the Earth's surface also 9 . So the main effect of solar flares to the radio noise level is increase of it. But intermediate frequency range - high frequencies (ranges between $1-30 \mathrm{MHz}$ ) has an opposite properties - the radiowaves propagating from the space can be reflected by the top part of the Earth's ionosphere and will not reach the Earth's surface. So the effects of solar flares in the HF bound can differ from the effects in higher and lower frequency bound.

Decameter noise usually is divided into 3 parts [24, 4]: atmospheric (generated mostly by lightings), anthropogenic (generated by human activity) and cosmic (generated outside the Earth) ones. Above $10 \mathrm{MHz}$ the most powerful noise mostly anthropogenic at daytime and mixture of atmospheric and anthropogneic during nighttime [24, 4.

The EKB ISTP SB RAS radar is similar by hardware and software with SuperDARN radars. The EKB radar was launched at the end of 2012 in the Sverdlovsk Region of the Russian Federation 3. Recently, the data from this radar have been used for the primary study of the effects of x-ray solar flares in passive mode [2. The results obtained allowed us to assume that the HF sky noise level measured by the radar anticorrelates with x-ray flare intensity.

In Fig 1 shown a fairly typical behavior of the daytime decameter sky noise level during a solar flare according to the EKB radar data at several directions of the antenna pattern (beams). One can see the decrease of the noise level (Fig,1A-E) during x-ray flare. Also one can see that temporal dynamics of the noise anticorrelates with x-ray flare intensity measured by GOES mission (Fig, $1 \mathrm{~F})$. As one can see from the figure, not every solar flare produces this effect (see the regions I. and II. at Fig 1 A-C).

Regular observations of the attenuation effect at EKB radar 2 allows us to assume that most part of of the sky noise is produced by terrestrial sources, and the most part of the noise comes from sources located at distances above the dead zone by sky wave mechanism (because the ground wave at HF range signifficantly attenuates with the distance). The propagation chractersitics at $\mathrm{HF}$ allows us also to suggest that the sources producing maximal intensity of the noise at the radar are located at the border of dead zone (at the range of groundscatter - the region that produces most intensive signal due to focusing of radiowaves in the ionosphere). So the noise is transmitted by the source, propagated by sky-wave, reflected from the ionosphere and absorbed at D-layer altitudes [19. The scheme for the qualitative explanation of the effect is shown in Fig, 1 .

In the paper the above hypothesis of dependence between HF sky noise level and x-ray solar flare intnesity is verified based on a large statistical dataset produced by 10 mid-latitude decameter radars in the northern hemisphere during 80 x-ray solar flares. 

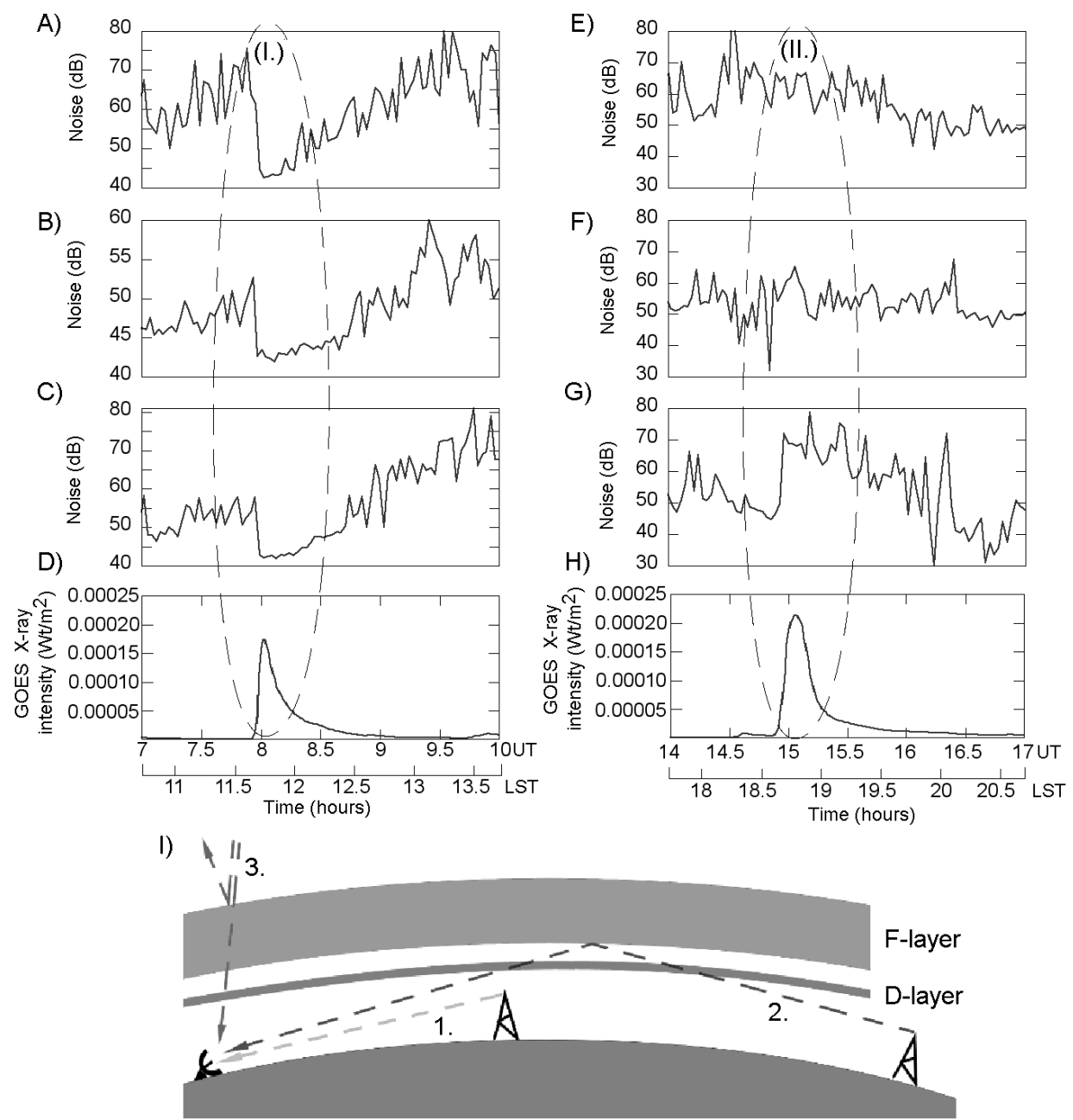

Figure 1: A-G) Dynamics of HF sky noise level based on EKB ISTP SB RAS radar data at different azimuths (beams) during two 25/10/2013 solar flares as a function of universal time and radar local solar time. A,E) - beam 15; B,F) - beam $7 ; \mathrm{C}, \mathrm{G}$ ) - beam 0 . Region I. is the presence of x-ray flare effect; region II. is absence of the x-ray flare effect. $\mathrm{D}, \mathrm{H}) \mathrm{X}$-ray intensity dynamics during the flares according to GOES 0.1-0.8 nm data; I) Illustration of the geometry of the experiment and an explanation of the trajectories of noise formation and propagation (1. - ground-wave noise; 2.-sky-wave noise; 3. cosmic noise). 


\begin{tabular}{|c|c|c|c|}
\hline Code & Radar & Coordinates & Owner \\
\hline ADW & Adak Island West, SuperDARN & $51.9 \mathrm{~N}, 176.6 \mathrm{~W}$ & Alaska Fairbanks, USA \\
ADE & Adak Island East, SuperDARN & $51.9 \mathrm{~N}, 176.6 \mathrm{~W}$ & Alaska Fairbanks, USA \\
BKS & Blackstone, SuperDARN & $37.1 \mathrm{~N}, 77.9 \mathrm{~W}$ & Virginia Tech, USA \\
CVE & Christmas Valley East, SuperDARN & $43.3 \mathrm{~N}, 120.4 \mathrm{~W}$ & Dartmouth College, USA \\
CVW & Christmas Valley West, SuperDARN & $43.3 \mathrm{~N}, 120.4 \mathrm{~W}$ & Dartmouth College, USA \\
EKB & Ekaterinburg, ISTP SB RAS & $56.5 \mathrm{~N}, 58.5 \mathrm{E}$ & ISTP SB RAS, Russia \\
FHE & Fort Hays East, SuperDARN & $38.9 \mathrm{~N}, 99.4 \mathrm{~W}$ & Virginia Tech, USA \\
FHW & Fort Hays West, SuperDARN & $38.9 \mathrm{~N}, 99.4 \mathrm{~W}$ & Virginia Tech, USA \\
HOK & Hokaido East, SuperDARN & $43.5 \mathrm{~N}, 143.6 \mathrm{E}$ & Nagoya University, Japan \\
WAL & Wallops, SuperDARN & $37.9 \mathrm{~N}, 75.5 \mathrm{~W}$ & JHU APL, USA \\
\hline
\end{tabular}

Table 1: List of radars, participated in the research

\section{Experimental setup and analysis techniques}

To verify the hypothesis, we used the data of 10 mid-latitude coherent decameter radars of the northern hemisphere: nine radars of the SuperDARN network (Super Dual Auroral Radar Network [12]) and the EKB ISTP SB RAS radar [3. The coordinates of the radars and their fields of view are shown in Fig.2. The basis of the radars operation is transmitting a seria of short pulses and receiving the signals backscattered by various inhomogeneities (both ionospheric and terrestrial ones). Each of the radar can operate at $8-20 \mathrm{MHz}$ frequency bound. Each radar can change the direction of main beam within its field of view (by changing the beam number - the azimuthal direction of the radar antenna pattern). Each beam width is about 3-6 degrees (depending on the radar frequency), the radar field of view is about 52 degrees. In addition to the basic mode of operation, each radar measures the intensity of background sky noise coming from the given direction. Usually, the radars operate near a fixed frequency, choosing the exact operation frequency as frequency with the lowest sky noise level. The radars record the noise level at the least noisy frequency, allowing subsequent analysis of the noise level. The regular temporal resolution of the radars is 1-2 minutes. As it will be shown later this temporal resolution is enough for analysis of temporal dynamics of HF sky noise during x-ray solar flares, used in this paper.

For analysis the following technique is used. Based on the GOES 0.1-0.8nm data, all the x-ray solar flares with intenisty exceeded $10^{-5} \mathrm{Wt} / \mathrm{m}^{2}$ during 20132017 years were selected. If several flashes were observed in the same day we investigate only the effects of the flare with a maximal amplitude. Using this approach 80 flares were found. The list of investigated days is shown in Table 2.

The distributions of flare maximal amplitudes and flare maximum moments are shown in Fig.3. The distributions are made separately over the universal time (Fig $3 \mathrm{~A}$ ) and over the local time for each beam of each radar (Fig $3 \mathrm{~B}$ ). The local time in this case corresponds to a point determined from two factors - 


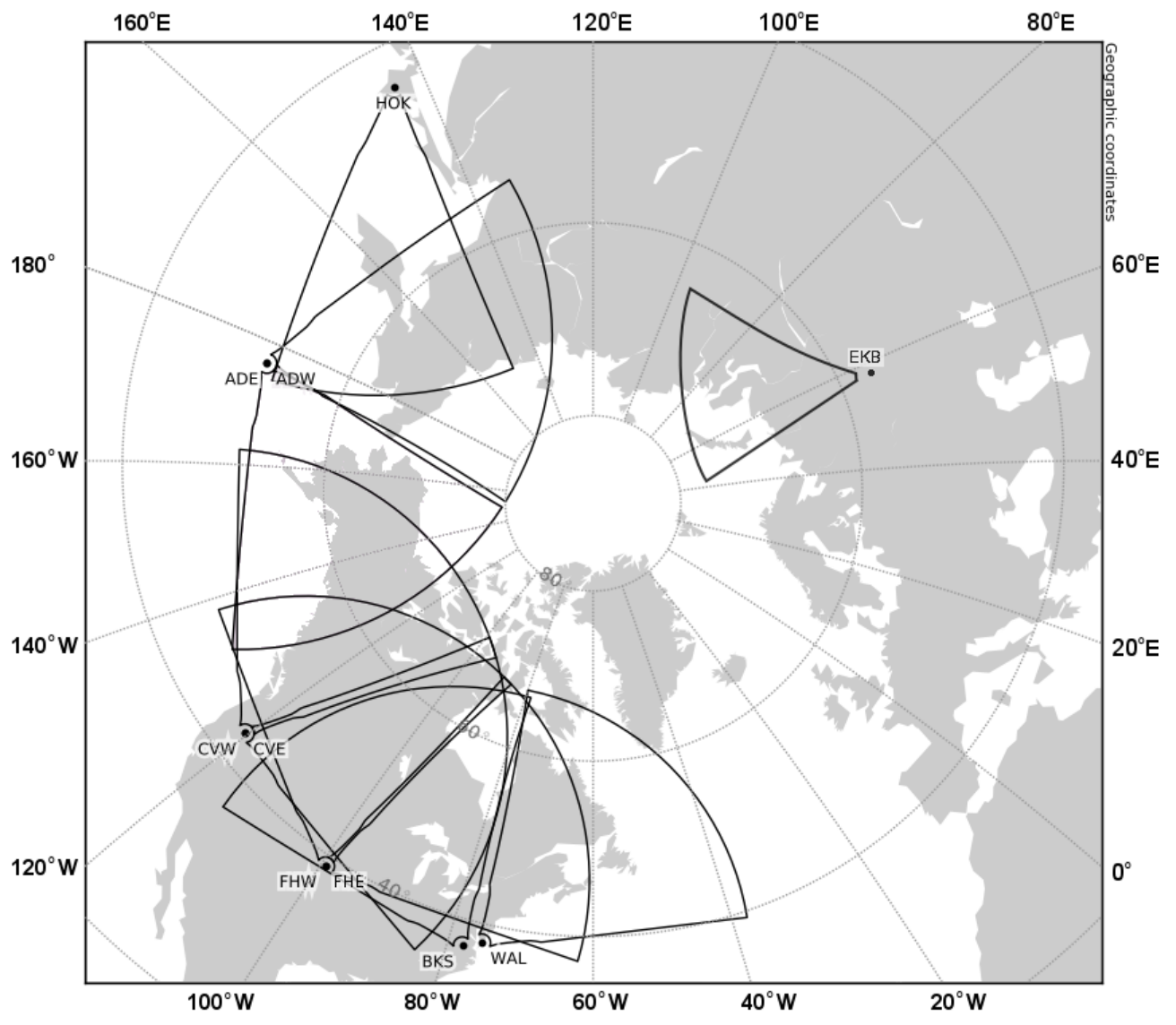

Figure 2: Radars used in the paper and their field-of-views 


\begin{tabular}{|l|l|l|l|l|l|}
\hline $2013-04-11$ & $2013-05-03$ & $2013-05-10$ & $2013-05-13$ & $2013-05-14$ & $2013-05-15$ \\
\hline $2013-06-07$ & $2013-10-24$ & $2013-10-25$ & $2013-10-28$ & $2013-10-29$ & $2013-11-01$ \\
\hline $2013-11-03$ & $2013-11-05$ & $2013-11-06$ & $2013-11-08$ & $2013-11-10$ & $2013-11-19$ \\
\hline $2013-12-31$ & $2014-01-01$ & $2014-01-07$ & $2014-01-27$ & $2014-01-28$ & $2014-01-30$ \\
\hline $2014-02-02$ & $2014-02-04$ & $2014-02-25$ & $2014-03-12$ & $2014-03-29$ & $2014-04-02$ \\
\hline $2014-04-18$ & $2014-04-25$ & $2014-05-08$ & $2014-06-10$ & $2014-06-11$ & $2014-07-08$ \\
\hline $2014-08-24$ & $2014-09-10$ & $2014-09-28$ & $2014-10-02$ & $2014-10-16$ & $2014-10-19$ \\
\hline $2014-10-20$ & $2014-10-22$ & $2014-10-24$ & $2014-10-25$ & $2014-10-26$ & $2014-10-27$ \\
\hline $2014-10-28$ & $2014-10-30$ & $2014-11-03$ & $2014-11-05$ & $2014-11-06$ & $2014-11-07$ \\
\hline $2014-11-16$ & $2014-12-04$ & $2015-01-13$ & $2015-03-02$ & $2015-03-03$ & $2015-03-07$ \\
\hline $2015-03-09$ & $2015-03-10$ & $2015-03-11$ & $2015-03-12$ & $2015-04-21$ & $2015-05-05$ \\
\hline $2015-06-21$ & $2015-06-22$ & $2015-06-25$ & $2015-08-22$ & $2015-08-24$ & $2015-09-28$ \\
\hline $2015-10-01$ & $2015-10-02$ & $2015-12-23$ & $2016-04-18$ & $2016-07-23$ & $2017-04-01$ \\
\hline $2017-04-02$ & $2017-04-03$ & & & & \\
\hline
\end{tabular}

Table 2: List of investigated x-ray solar flares

the radar beam direction (most of the radars have 16 directions in their field-ofview), and the distance from the radar to dead zone (or groundscatter distance) $\sim 1500 \mathrm{~km}$. The dead zone distance is chosen due to signal from a source can not approach a receiver by sky-wave mechanisms at distances smaller than this. The approximation is very rough, since the distance of the dead zone can vary from 500 to $3000 \mathrm{~km}$, depending on the background ionospheric conditions and the radar operating frequency. However, as further analysis shows, our approximation allows us to obtain sufficiently convincing statistical results.

Therefore for each radar, each beam and each flare the daily dependence of the noise is collected. As one can see in Fig $3 \mathrm{C}-\mathrm{D}$, the amount of the data collected by this way becomes quite large (the average number of experiments studied for each hour is about 300) and pretty complete (the minimal number of experiments for each hour is $\sim 250$ ).

The distribution of radar operating frequencies during the investigated solar flares is shown in Fig $3 \mathrm{E}-\mathrm{F}$. From the Fig $3 \mathrm{~F}$ one can see that radars operated mostly in two bands: $10-12 \mathrm{MHz}$ and $13-15 \mathrm{MHz}$, with nearly absence of significant daily dependence of distributions (Fig $3 \mathrm{E}$ ). Thus, the data analyzed by us in this paper relate mostly to operating frequencies $10-15 \mathrm{MHz}$.

Thus, we collected the statistics of observations of 80 solar flares in more than 150 spatial points each. As a result we collected about 13000 daily measurements for statistical analysis. In Fig $3 \mathrm{E}-\mathrm{F}$ is shown distribution of solar flare duration calculated at $e^{-1}$ level from maximal intensity. As one can see from Fig $3 \mathrm{E}-\mathrm{F}$, the duration of each of the flares does not exceeds 1.5 hour, with an average value about $20 \mathrm{~min}$. This allows us to differ flare effects and daily noise dynamics by filtering. Also it allows us to use standard radar temporal resolution mode $1-2$ min for investigating the x-ray flares effects.

From the pairs date-radar we excluded the following experiments, during which the observed noise is too low or too high: 2015-03-09(WAL); 2015- 


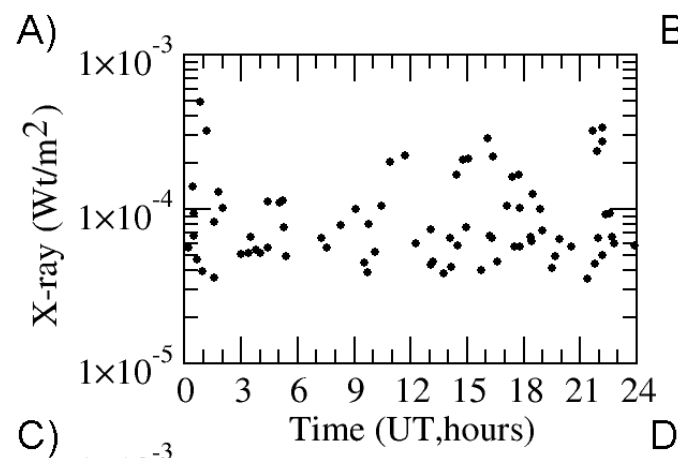

B)
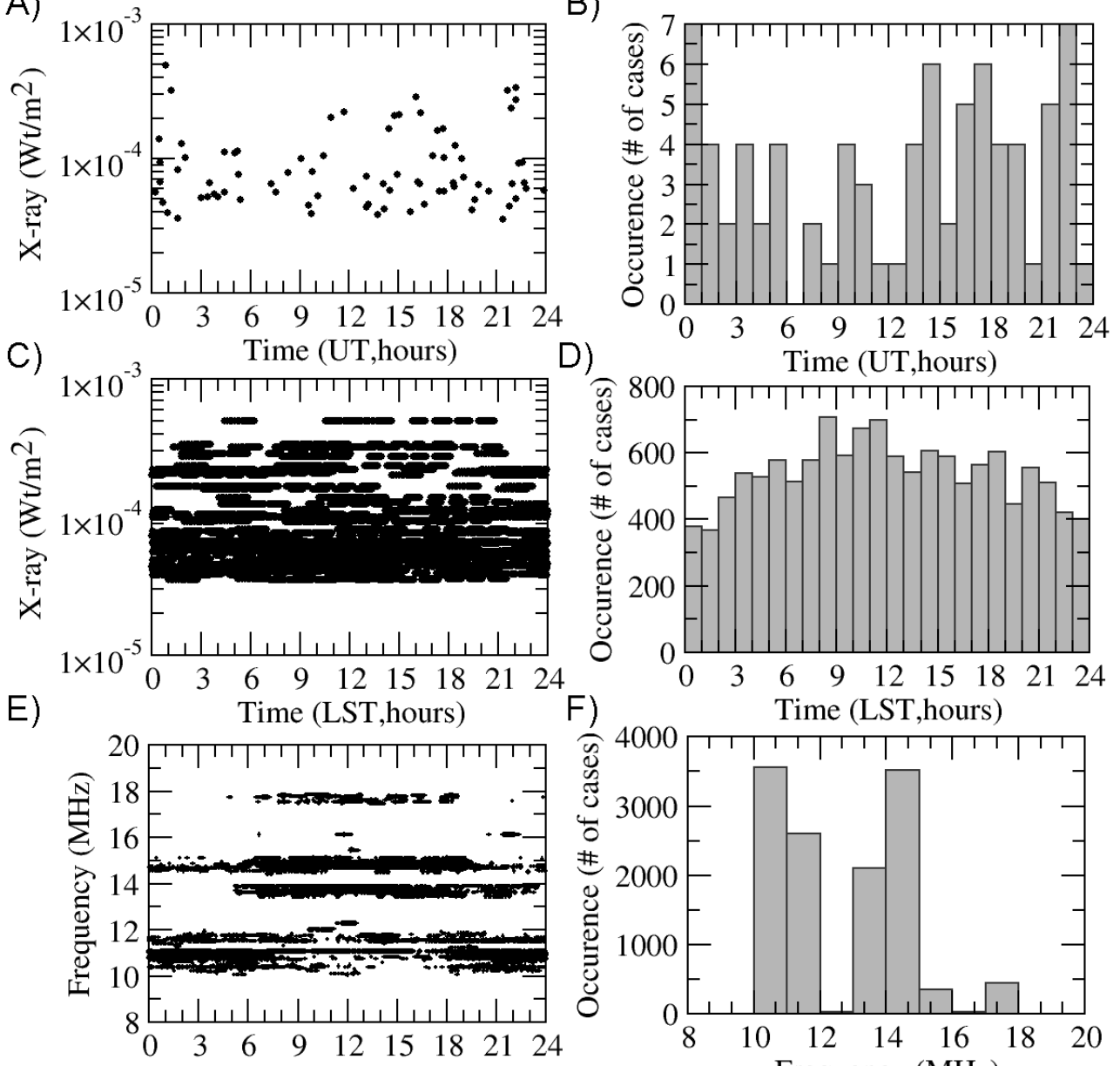

G)
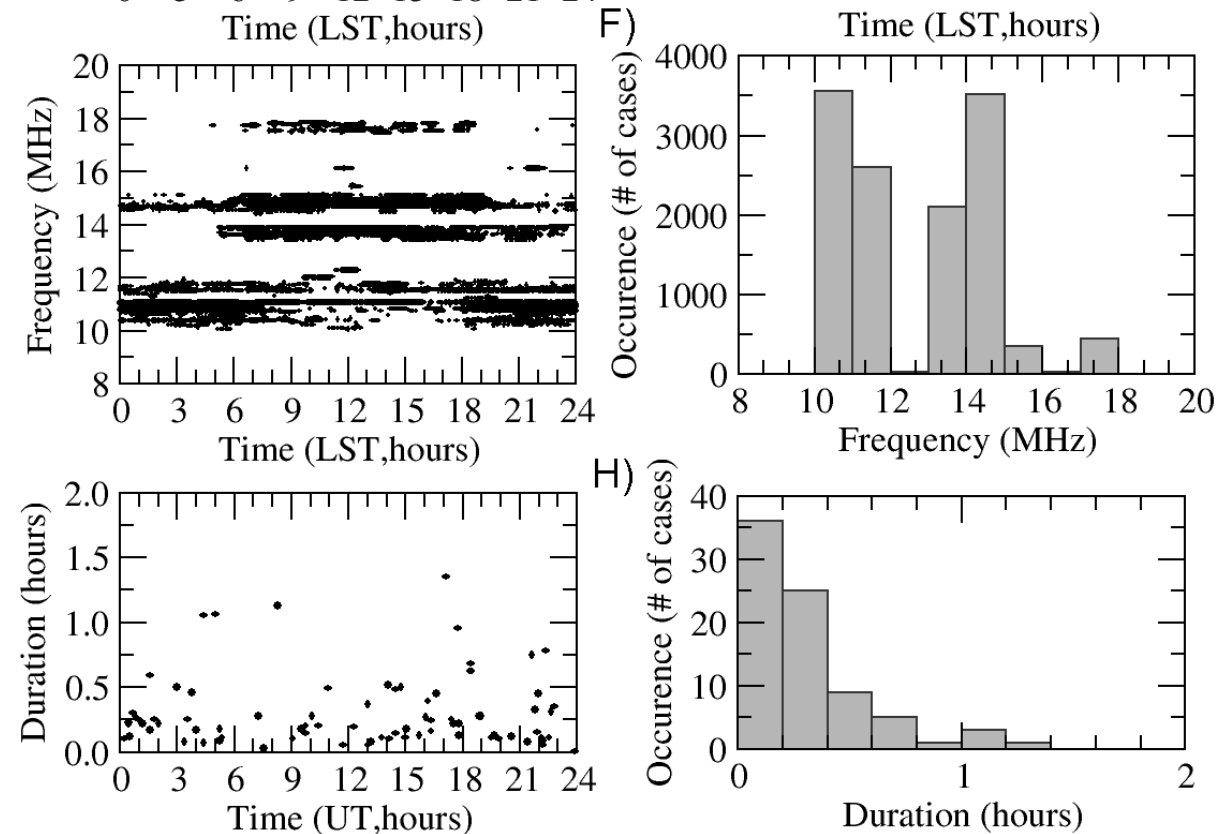

H)

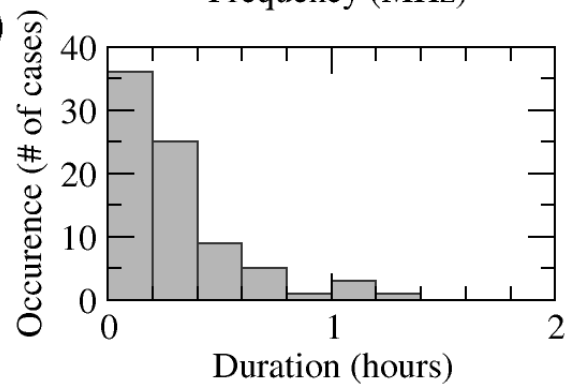

Figure 3: $(\mathrm{A}, \mathrm{C})$ - the distributions of $\mathrm{x}$-ray solar flares analyzed in the paper over maximal amplitude, as a function of the universal time $(\mathrm{A})$ and as a function of the local solar time (C), and (B, D) - solar flares maximal amplitudes as functions of the universal time (B) and the local solar time (D). E) - distribution of radar operating frequencies during solar flares, as a function of the local solar time F) - statistical distribution of radar operating frequencies during solar flares. E)-F): distributions of flare durgtion (at $e^{-1}$ level): E) - as function of UT, F) - statistical distribution. 
03-09(BKS); 2015-03-10(WAL); 2015-03-10(BKS); 2015-03-11(BKS); 2015-0311(WAL); 2014-04-18(FHE); 2014-04-18(FHW); 2015-08-22(CVW); 2015-06-22(FHE); 2015-08-24(CVW). Low and high noise can identificate that some not regular experiments of radar modes are carried out.

In Fig 2 shown noise distribution at each radars accumulated over all the beams and over all the investigated days as a function of local solar time. As one can see, the noise dynamics differs from one radar to another and has significant dynamics and mean square variation (the variations of the noise intensity exceed 20-25dB). This can be caused by a set of factors: the changes of operating frequencies at each radar, different location and anthropogenic neighborhood, different radar hardware. High noise dynamics and variability do not allow us to use average or median values of the noise, calculated over all the experiments to accurately investigate solar flares effects. So to analyze the flare effect one should remove background noise dynamics from the data for each day and each beam separately. To do this we use the following algorithm.

To detect the effects of solar flares a correlation and regression analysis was performed between the diurnal variation of the noise and the flare intensity variation. The same was done for each day, for each radar and for each radar beam. Since the intensity of the received signal depends on the absorption exponentially [9, we analyzed the relationship between the intensity of solar radiation in $W t / m^{2}$ and the noise intensity in $\mathrm{dB}$. Changes of radar sounding modes (in particular, the radar operating frequency or noise frequency) for each radar was not taken into account to increase the time resolution of the radar data.

To exclude the observed slow daily dynamics of sky noise, the slow varying component of the noise level was removed from the noise intensity $N(t)$ using an infinitive impulse response (IIR) filter with the impulse response $e^{-t / \Delta T}$ (where $\Delta T$ is about 1 hour, exceeding everage flare duration). The resulting function $Y(t)$ is a relatively fast variation of the noise level with periods of less than 1-2 hours:

$$
Y(t)=10\left\{l g(N(t))-\frac{1}{\Delta T} \int_{-\infty}^{t} \lg (N(\tau)) e^{-(t-\tau) / \Delta T} d \tau\right\}
$$

To estimate the correlation between filtered noise $(Y(t))$ dynamics and x-ray intensity $(X(t))$ dynamics, the Pearson correlation coefficient $R$ was used:

$$
\begin{gathered}
R=\frac{\int_{T_{0}-2 \Delta T}^{T_{0}+2 \Delta T}(X(t)-\langle X\rangle)(Y(t)-\langle Y\rangle) d t}{\sqrt{\int_{T_{0}-2 \Delta T}^{T_{0}+2 \Delta T}(X(t)-\langle X\rangle)^{2} d t \int_{T_{0}-2 \Delta T}^{T_{0}+2 \Delta T}(Y(t)-\langle Y\rangle)^{2} d t}} \\
\langle X\rangle=\frac{1}{4 \Delta T} \int_{T_{0}-2 \Delta T}^{T_{0}+2 \Delta T} X(t) d t \\
\langle Y\rangle=\frac{1}{4 \Delta T} \int_{T_{0}-2 \Delta T}^{T_{0}-2 \Delta T} Y(t) d t
\end{gathered}
$$

The Pearson correlation coefficient $R$ was calculated over the period $+/-2 \mathrm{~h}$ from the moment $T_{0}$ of the maximal flare intensity. The correlation coefficient $R$ is within $[-1 . .1]$ and defines the degree of correlation between the noise intensity 

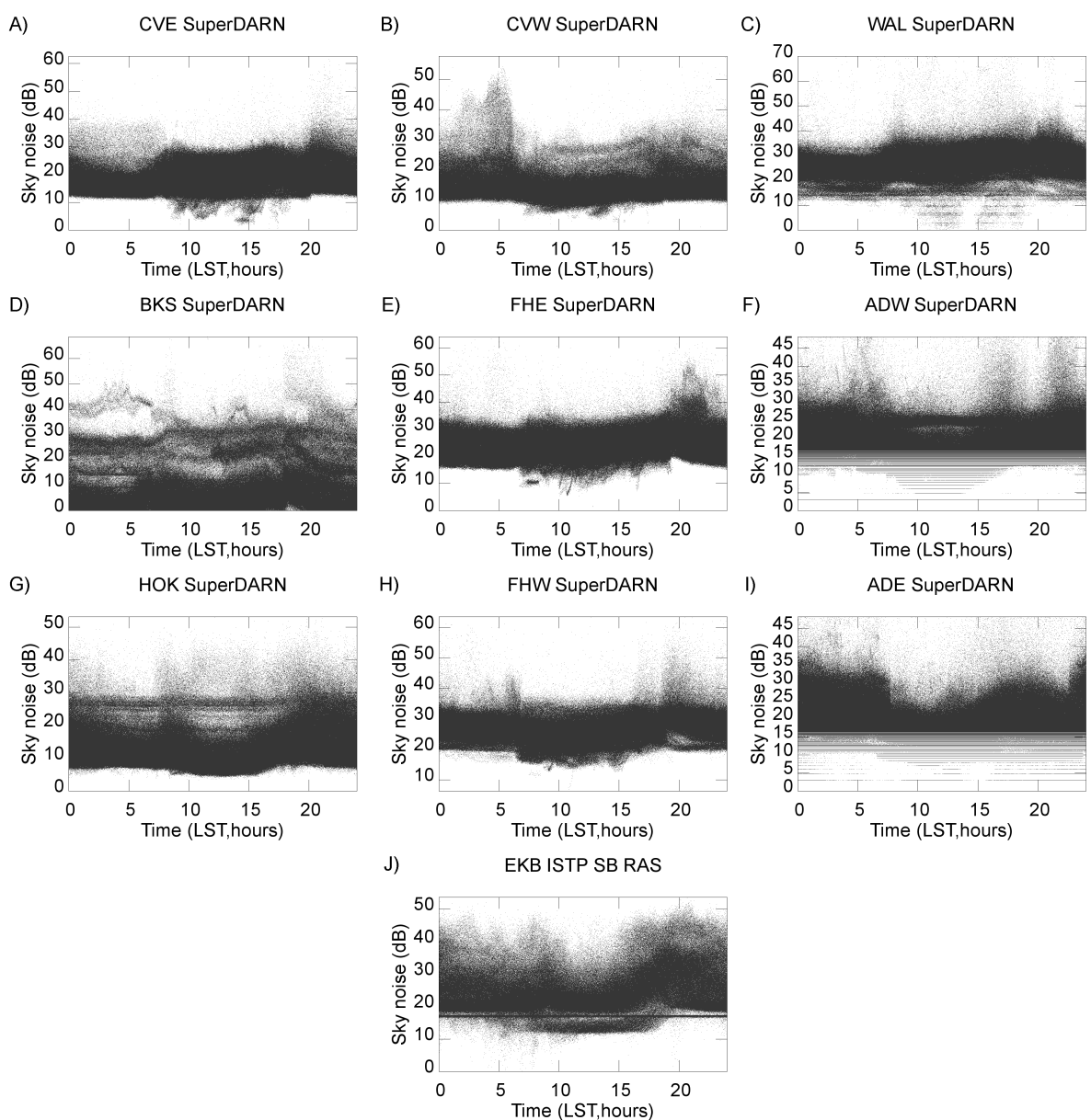

Figure 4: Noise distribution for different radars averaged over all the beams and over all the investigated days as a function of local solar time 
and the intensity of solar radiation during the flare. For high values $|R|>0.5$, the correlation is significant and the two characteristics can be considered as correlating well.

To study the proportionality of the logarithm of noise and the intensity of the X-ray radiation during the flare, a regression analysis was performed for each of the 13000 diurnal observations. According to the method of least squares, the proportionality coefficient between the variations of noise intensity and the variations of flare intensity is defined as:

$$
Y(t) \approx A X(t)+Y_{0}
$$

where

$$
A=\frac{\int_{T_{0}-2 \Delta T}^{T_{0}+2 \Delta T}(X(t)-\langle X\rangle)(Y(t)-\langle Y\rangle) d t}{\int_{T_{0}-2 \Delta T}^{T_{0}+2 \Delta T}(X(t)-\langle X\rangle)^{2} d t}
$$

and $Y_{0}$ - some constant, unimportant for future analysis.

The resulting value of $A$ is regression coefficient between the variations of the noise intensity and the intensity of the x-ray flare.

\section{Results}

Based on the selected set of $~ 13000$ daily measurements by 10 radars, as well as based on GOES X-ray measurements in the range 0.1-0.8 nm during 80 flares, we performed correlation and regression analysis according to approach (115). The resulting values of the correlation coefficient $R$ are analyzed as a function of local solar time LST (LST was determined from the position of the radar, the direction of the beam of the radar antenna pattern and for effective attenuation range $1500 \mathrm{~km})$. The results of the correlation analysis are shown in Fig.5. From Fig 5 A-B one can see that the most part of experiments $(\sim 2 \%)$ produces the correlation coefficient $-0.5 \leq R \leq 0.5$. Usually this can be interpreted as statistically not correlated variations of the sky noise and intensity of solar $\mathrm{x}$-ray flares. Nevertheless, from the statistical distribution of the correlation coefficients as a function of local time (shown in Fig.5B) one can see significant asymmetry and negative offset of the correlation coefficient ( $R<0$ in $68 \%$ cases) and the average value of correlation coefficient $R$ is about $-0.21 \pm 0.29$. This can be interpreted as a sign of predominant attenuation of HF sky-noise during $\mathrm{x}$-ray solar flares.

The observed statistical effect confirms our preliminary results 2, used for the research motivation.

In Fig 5D one can see that the correlation coefficient exceeds the limits [0.5..0.5] mostly during daytime 07-19LST. Daytime observations (07-19LST) correspond to about $93 \%$ of all the observations with $|R|>0.5$. The median moment of observations with $|R|>0.5$ corresponds to $11: 30 \mathrm{LST}$ with quartiles at $~ 09: 30 \mathrm{LST}$ and $\sim 14: 30 \mathrm{LST}$. This means that most of the cases with strong correlaion between sky-noise and x-ray intensity corresponds to daytime, and 
the effect is centered near the solar noon. This allows us to suggest that the effect is really connected with the Sun activity and arises in the radar vicinity.

In Fig $5 \mathrm{E}$ shown dependence of Pearson correlation coefficient on solar elevation angle. As one can see, during daytime (54\% of cases) the correlation significantly intensify. In Fig $5 \mathrm{E}$ shown the distribution of Pearson correlation coefficient for positive elevation angles (i.e. during daytime). As one can see during daytime the strong negative correlation of the effect is more clear that at whole statistics (Fig $5 \mathrm{~B})$.

It should be noted that most part of the daytime data $(67 \%)$ is poorly correlated with the solar flare $(|R|<0.5)$. Nevertheless, the negative correlation $(R<0)$ is observed in $88.3 \%$ of all the daytime cases, and $R<-0.5$ is observed in $33 \%$ of all the daytime cases. This indicates that daytime noise is attenuated by x-ray solar flare, but there can be a significant dependence of the magnitude of the effect on other parameters, for example, from the initial level of background noise, from the geometry of terrestrial noise sources, as well as from the local atmospheric and ionospheric conditions near the radar.

In Fig.6A shown the dependence of attenuation of sky noise on the x-ray intensity for good correlation $(|R|>0.5)$. One can see that there is apparently no linear regression between noise level attenuation and x-ray flare intensity. But there is an obvious tendency to increase noise attenuation during the daytime flares (Fig $6 \mathrm{~B})$. The average regression coefficient for $|R|>0.5$ is about $(-6.9 \pm$ $10.9) \cdot 10^{4}\left[\mathrm{~dB} \cdot \mathrm{m}^{2} / \mathrm{Wt}\right]$. The average regression coefficient for $|R|>0.7$ is about $(-9.9 \pm 9.5) \cdot 10^{4}\left[d B \cdot m^{2} / W t\right]$.

The big mean square error shows that distribution is too wide to be estimated it by mean value. The distribution of the regression coefficients $\mathrm{A}$ and their daily dependence are shown in Fig 6 B-C. As one can see, the distribution is wider than average value, but most part of it is negative. This allows us to conclude that during well correalting $(|R|>0.5)$ experiments the noise attenuates during x-ray flares. The distribution of the regression coefficient $A$ also shows the negative median regression coefficient for $(|R|>0.5): A \approx-6.9 \cdot 10^{4}\left[\mathrm{~dB} \cdot \mathrm{m}^{2} / W t\right]$ with quartiles $-4.2 \cdot 10^{4},-11.2 \cdot 10^{4}\left[\mathrm{~dB} \cdot \mathrm{m}^{2} / W t\right]$. For $(|R|>0.7)$ median value reaches $A \approx-8.0 \cdot 10^{4}\left[\mathrm{~dB} \cdot \mathrm{m}^{2} / \mathrm{Wt}\right]$ with quartiles $-5.8 \cdot 10^{4},-12.4 \cdot 10^{4}\left[\mathrm{~dB} \cdot \mathrm{m}^{2} / \mathrm{Wt}\right]$.

In Fig $6 \mathrm{E}$ shown dependence of regression coefficient $A$ on solar elevation angle during daytime. As one can see there is a slight increase of regression coefficient with increase of the solar elevation angle. This can be explained by an increase in the ionization level with an increase in the solar elevation angle and explains the increase of regression coefficient at noon (Fig $6 \mathrm{~B})$.

In Fig $6 \mathrm{~F}$ shown the statistical distribution of regression coefficient $A$ during daytime - for positive solar elevation angles. Average regression coefficient $A$ during daytime is $-5.3 \cdot 10^{4}\left[\mathrm{~dB} \cdot \mathrm{m}^{2} / W t\right]$ with mean square error $7.5 \cdot 10^{4}[\mathrm{~dB}$. $\left.\mathrm{m}^{2} / W t\right]$. Median value of $A$ is $-4.4 \cdot 10^{4}\left[\mathrm{~dB} \cdot \mathrm{m}^{2} / W t\right]$ with quartiles -1.5 . $10^{4}\left[\mathrm{~dB} \cdot \mathrm{m}^{2} / \mathrm{Wt}\right],-8.6 \cdot 10^{4}\left[\mathrm{~dB} \cdot \mathrm{m}^{2} / \mathrm{Wt}\right]$.

At nighttime the average $R$ is about -0.04 , and median $A$ is $-6.3 \cdot 10^{3}[d B$. $\left.m^{2} / W t\right]$ i.e. there is almost no signifficant correlation between solar xray flare and noise attenuation at night. The nighttime regression coefficient $A$ is about ten times smaller than daytime $A$, that also shows the greater importance of 

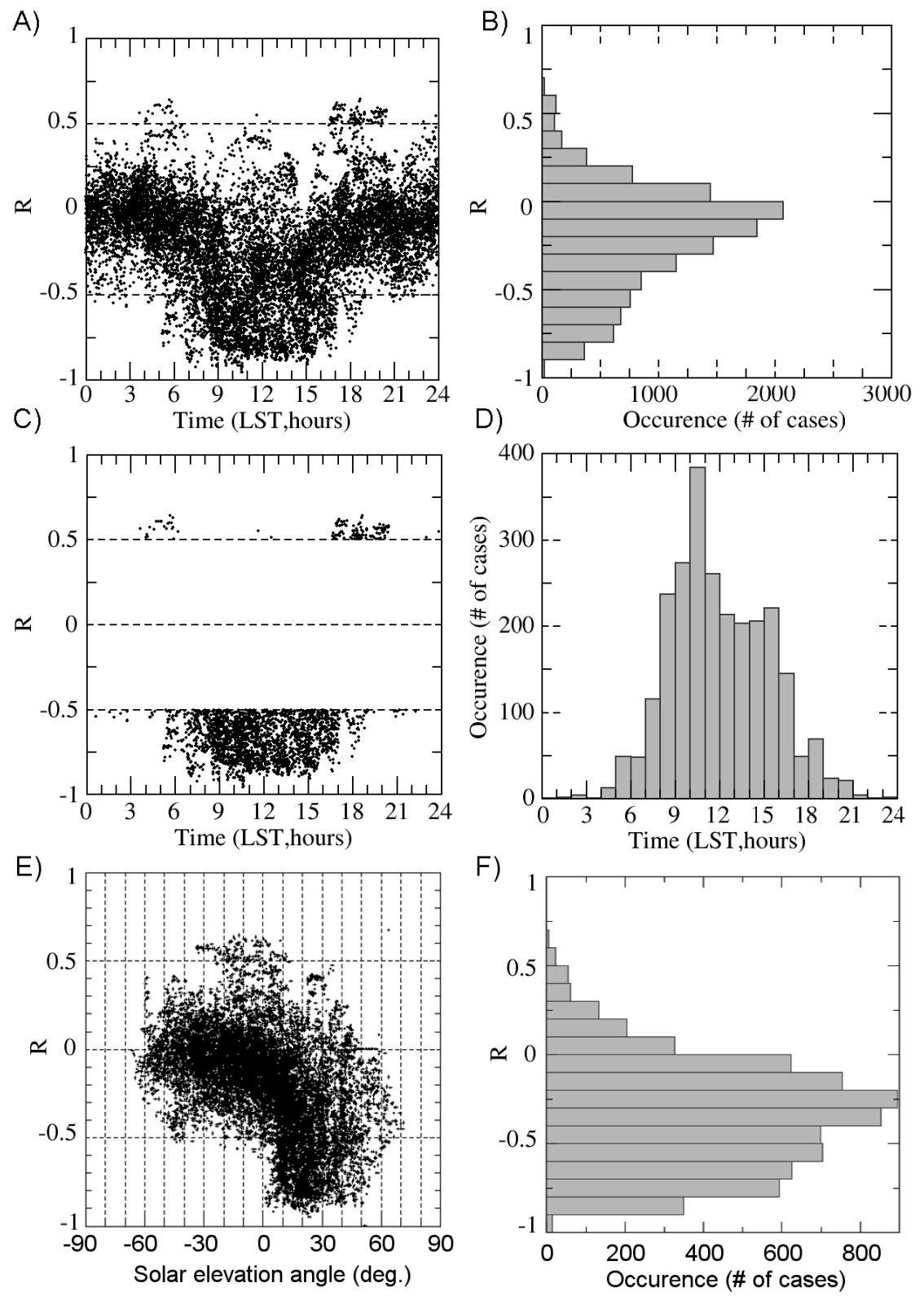

Figure 5: A) - Pearson correlation coefficients between the measured sky noise and x-ray flare intensity for different experiments as a function of local solar time B) - Statistical distribution of Pearson correlation coefficients. C) - Experiments with significant Pearson correlation $(|R|>0.5)$ between measured sky noise and x-ray flare intensity as a function of local solar time. D) Local solar time distribution of cases with significant Pearson correlation $(|R|>0.5)$ E) Dependence of Pearson correlation coefficient on solar elevation angle F) Distribution of Pearson correlation coefficient for positive elevation angles 
the daytime effect than the nighttime effect.

Let us interpret this. Solar xray radiation mostly effects at illuminated part of the Earth's ionosphere. If the far-range noise sources makes the main contribution into the sky-noise, measured by the radar, the effect should not significantly depend on radar local solar time. But according to experimental data (Fig $6 \mathrm{E}$ ) the strong effect exists only when the radar is at dayside. This allows us to exclude from consideration the sources of the noise, located too far from the radar, and suppose that the main contribution to the radar noise is made by the sources located near the radar (we expect about $1500 \mathrm{~km}$ ).

\section{Discussion and conclusion}

Our statistical analysis of the Pearson correlation coefficient $(R)$ and the regression coefficient $(A)$ of 80 x-ray flares at 10 mid-latitude HF radars, about 16 directions for each (which is equivalent to about 13000 individual experiments) shows that there is a certain tendency ( $88.3 \%$ of daytime experiments) to attenuate daytime HF noise level during x-ray solar flares, about $34 \%$ of the attenuation profile correlates well $(|R|>0.5)$ with x-ray intensity profile. So the attenutation of the daytime HF noise during solar xray flates can be interpreted as a regular effect. During nightime the sky-noise attenutation is observed in $62 \%$ of cases, and in the most of the cases $(97.6 \%)$ the attenuation profile is poorly correlating with $\mathrm{x}$-ray intensity profile $(|R|<0.5)$. So the nighttme effects in comparison with daytime effect can be neglectable.

Fig 7 shows illustrative examples of noise attenuation during solar flares at various radars for good Pearson coefficient $(R<-0.5)$. The figure illustrates a good correlation of the temporal dynamics of X-ray radiation and the dynamics of sky noise level, which confirms with the statistically observed tendency to high anticorrelation between them (shown in Fig,556).

As it can be seen from Fig.7F, I, the minimal self-noise of the receivers usually is about $1-10 \mathrm{~dB}$ (this corresponds to the lowest 3 bits of digital signal). When sky noise intensity becomes lower than $10 \mathrm{~dB}$ level it becomes hard to investigate the noise dynamics. In Fig 8 the possible sources of errors in calculation of regression coefficient $A$ are illustrated. They are: the own dynamics of sky noise intensity is not taken into account correctly (Fig $8 \mathrm{~A}-\mathrm{C}$ ); the presence of additional noises, not affected by flare and too powerful effect causing saturation effect during flare maximum (Fig $8 \mathrm{C}, \mathrm{D}-\mathrm{F})$. In Fig $8 \mathrm{E}$ the effect of saturation is shown more clear: the x-ray intensity is fitted without taking into account saturation effect (black dashed line) and with taking into account the possibility of saturation effect (black solid line). As one can see, the results are different, so taking into account saturation effect increase regression coefficient value $A$.

In Fig.1] shown the proposed interpretation of the observed effect, similar to well known explanation of HF absorbtion of radiowave signals [19]. Decameter radiowaves from closely located sources does not reflect from the ionosphere and does not attenuate in its lower part (trajectory 1 in Fig 11). Decameter ra-

diowaves outside the dead zone reflects from the ionosphere and passes through 

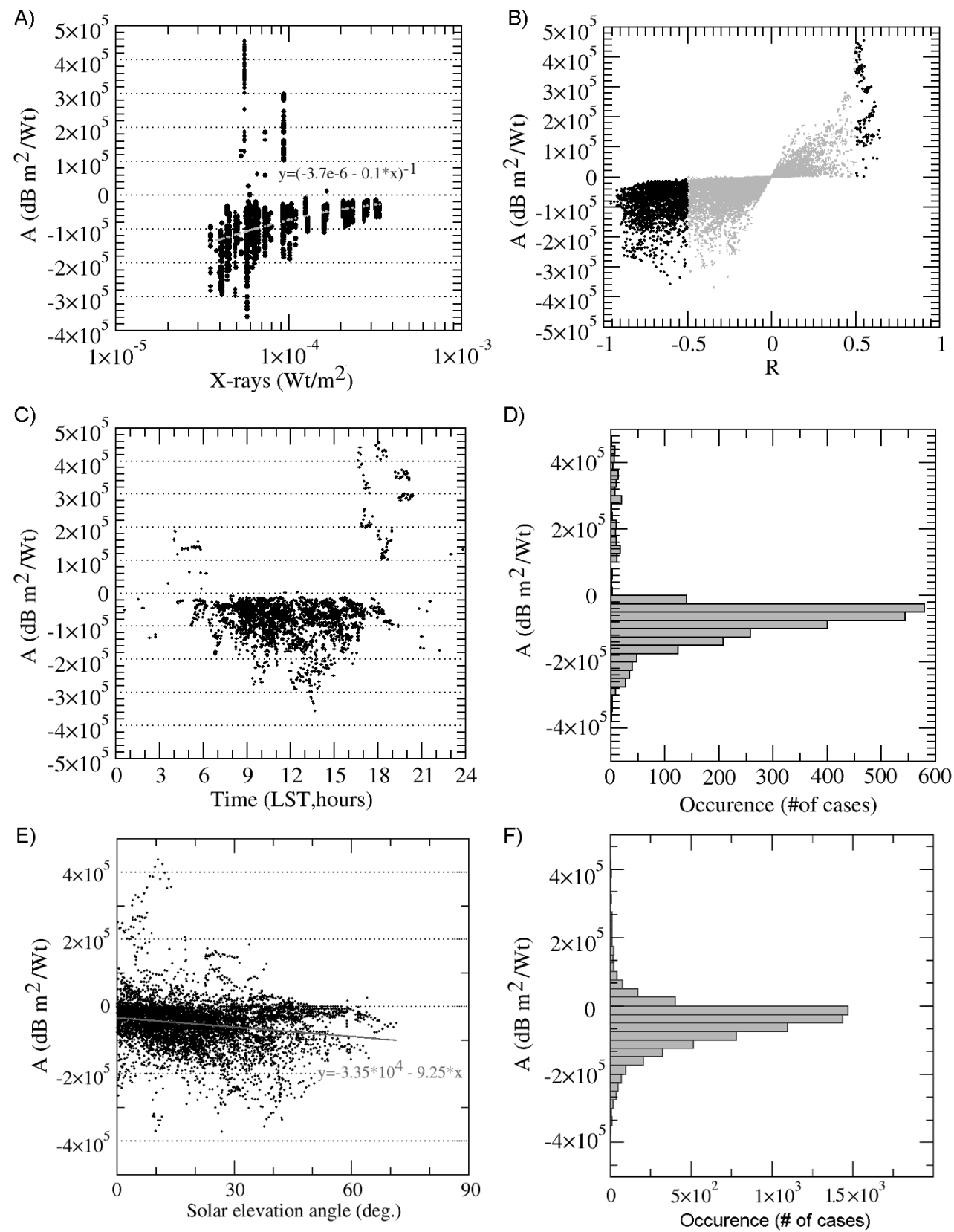

Figure 6: $(\mathrm{A})$ is the regression dependence between the intensity of the effect in the HF sky noise and the x-ray intensity of the flare for the good correlating experiments $(|R|>0.5)$; (B) - dependence of regression coefficient $A$ on correlation coefficient $R$; (C-D) is the statistics of regression coefficient A (5): its dependence on the local time $(\mathrm{C})$ and its statistical distribution (D); (E) dependence of regression coefficient $A$ on solar elevation angle; (F) - statistical distribution of regression coefficient $A$ for positive solar elevation angles. 
A) $03 / 05 / 2013$, CVE SuperDARN

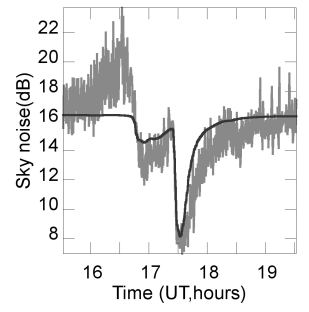

D) $03 / 05 / 2013$, BKS SuperDARN

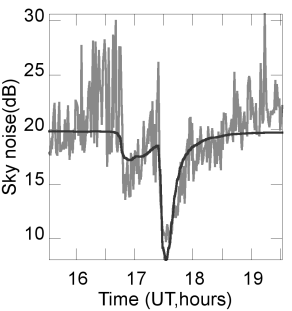

G) 11/04/2013, HOK SuperDARN

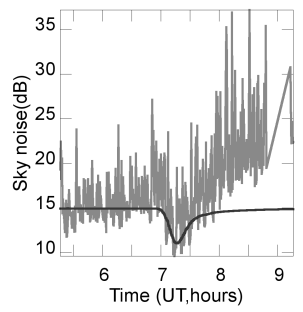

B) $07 / 01 / 2014$, CVW SuperDARN

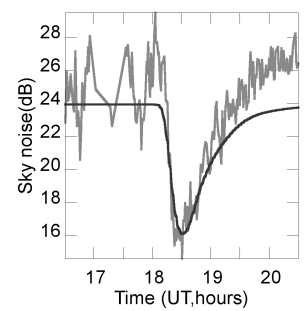

E) $07 / 01 / 2014$, FHE SuperDARN

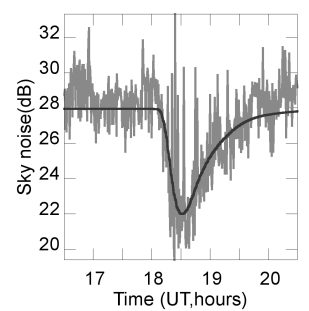

H) 02/04/2014, FHW SuperDARN

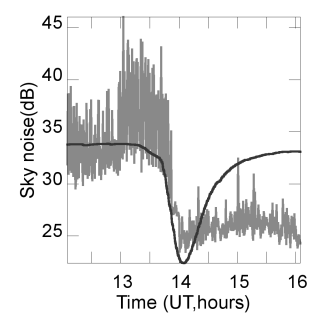

J) $18 / 04 / 2014$, EKB ISTP SB RAS

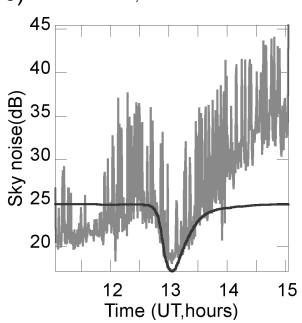

C) $07 / 06 / 2013$, WAL SuperDARN

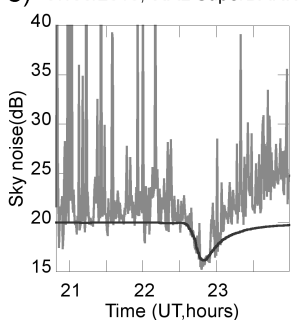

F) $02 / 04 / 2017$, ADE SuperDARN

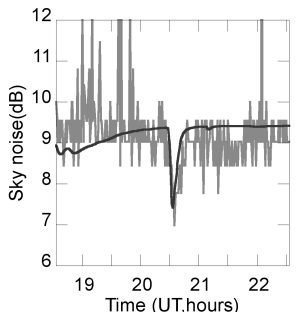

I) $02 / 04 / 2017$, ADW SuperDARN

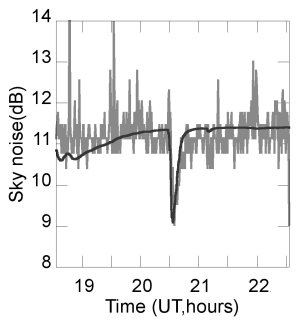

Figure 7: Examples of daytime sky noise dynamics at different radars during different x-ray solar flares (for cases with good Pearson correlation coefficient $R<-0.5)$. Red line - GOES x-ray intensity (normalized), green line - sky noise dynamics. 
A) $05 / 11 / 2014$, EKB ISTP SB RAS

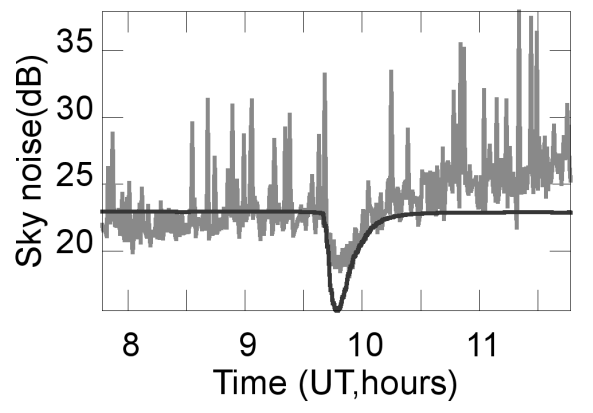

B) $02 / 04 / 2014$, FHE SuperDARN

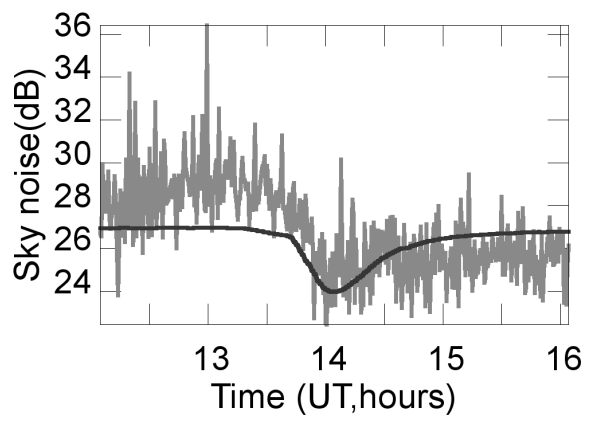

C) $12 / 03 / 2014$, HOK SuperDARN

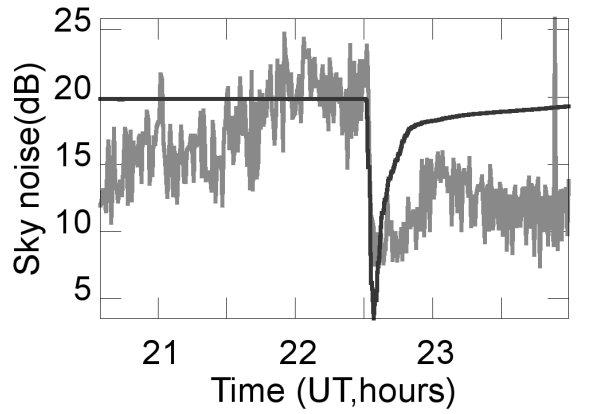

D) $24 / 10 / 2014$, FHW SuperDARN

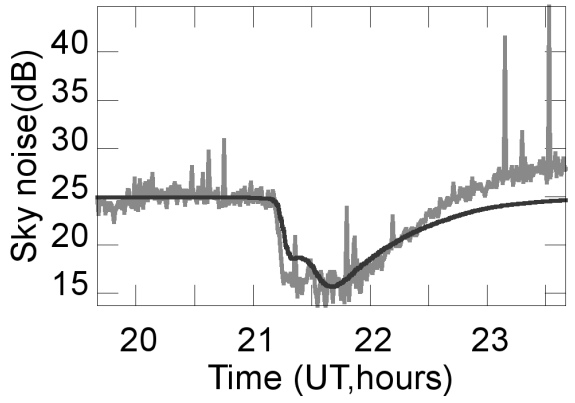

E) $14 / 05 / 2013$, ADW SuperDARN

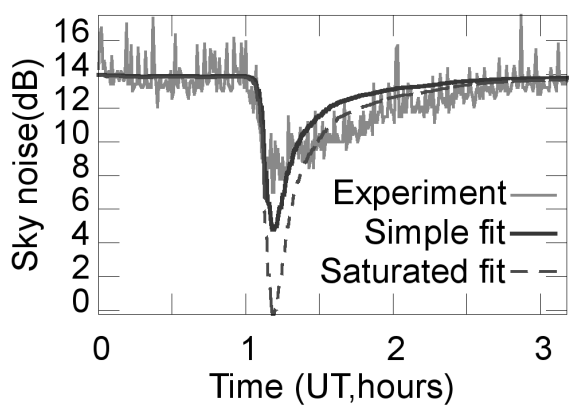

F) 13/05/2013, CVE SuperDARN

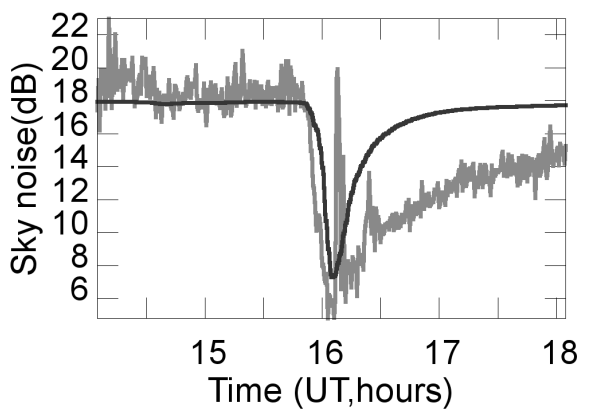

Figure 8: Sources of errors in calculation of A. A-C) - Sky noise dynamics effect; D-F) - saturation effect; E) - illustration of saturation effect at ADW 14/05/2013 data example: gray line - experimental data; black line - fitted x-ray intensity without taking into account presence of saturation effect; dashed line - fitted $\mathrm{x}$-ray intensity with taking into account presence of saturation effect. 
the ionospheric D-layer twice, having substantial absorption during the x-ray solar flares due to additional D-layer ionization (trajectory 2 in Fig 1 I). The direct solar radiation in the $\mathrm{HF}$ range to the receiver falls or passes depending on the ionospheric conditions - when the operating frequency is below the plasma frequency f0F2 - it is reflected back, and when the operating frequency is higher than f0F 2 - it passes (trajectory 3 in Fig.1 $)$. Most often (Fig $5 \mathrm{~B}$.6C) the combination of all these mechanisms is observed as attenuation of the HF sky noise, and this attenuation in the logarithmic scale nearly repeats the shape of the $\mathrm{x}$ ray intensity during the flare (Fig 7). Dependence of noise effects on the radar beam (azimuth,Fig, 1A-C,E-G) allows us to neglect the cosmic noise role in the effect. This indicates the predominance of the mechanism of over-the-horizon noise propagation from terrestrial (anthropogenic) sources over the effects of cosmic noise and ground-wave noise in the investigated frequency range of 10$15 \mathrm{MHz}$ during solar x-ray flares. Thus, it can be assumed that in this case the influence of anthropogenic noise sources is significant and should be taken into account when interpreting the data.

The median regression coefficient $A$ between HF sky noise and $0.1-0.8 \mathrm{~nm}$ GOES x-ray intensity during daytime is about $-4.4 \cdot 10^{4}\left[\mathrm{~dB} \cdot \mathrm{m}^{2} / W t\right]$. The significant contrast between regression coefficient $A$ and constant value (Fig $6 \mathrm{~A}$ ) can be associated with many effects, that requires future investigations and corrections - mostly these are: HF sky noise dynamics; non-linear regression dependence including saturation effect due to powerful flares; additional noise, not affected by ionosphere. Another reason for possible errors in calculations of $A$ is the irregular changes of the radar operational frequency in the standard scanning mode. This can also lead to additional variations in the amplitude

of the noise and to increase of errors. Also there is shown a slight increase of regression coefficient $A$ with solar elevation angle. This can be explained by increase of ionization with increase of solar elevation angle.

Thus, in the paper shown that daytime short-wave noise during solar flares in $88.3 \%$ of cases attenuates, which can be explained by terrestrial (anthropogenic) source of HF sky noise. As one can see the regression coefficient $A$ between x-ray intensity and noise intensity in logarithm scale is useful parameter for describing the ionospheric absorption effects during x-ray solar flares. Therefore, HF sky noise level dynamics can be used to monitor ionospheric effects during x-ray solar flares by mid-latitude decameter radars, and these radars can be used as a kind of mid-latitude riometers to investigate reaction of D-layer to x-ray solar flares.

\section{Acknowledgments}

In the paper we used the data of EKB ISTP SB RAS, operating under financial support of FSR Program II.12.2.3. The SuperDARN Hokkaido East is the property of Nagoya University and its construction/operation has been funded by the Ministry of Education, Culture, Sports, Science and Technology of Japan. O.B. is supported by Presidium RAS Program \#31 (Project Number: \#0344- 2014- 
0022), N.N. is supported by Japan Society for the Promotion of Science (JSPS), "Grant-in-Aid for Specially Promoted Research" (Project Number: 16H06286).

The data of the SuperDARN radars were obtained using the DaViT (https:// github.com/ vtsuperdarn/ davitpy), the EKB ISTP SB RAS radar data are the property of the ISTP SB RAS, contact Oleg Berngardt (berng@iszf.irk.ru). The authors are grateful to NOAA for providing the GOES data. The authors are grateful to all the developers of the DaViT system, in particular K.Sterne, N.Frissel, S. de Larquier and A.J.Riberio, as well as to all the organizations supporting the radars operation.

\section{References}

[1] Baker J., Greenwald R.,Ruohoniemi J. , Oksavik K. , Gjerloev J.W. , Paxton L.J. ,Hairston M. . Observations of ionospheric convection from the Wallops SuperDARN radar at middle latitudes. Journal of Geophysical Research (Space Physics) 2007;V.112:pp.A01303. DOI:10.1029/2006ja011982.

[2] Berngardt O. , Kutelev K. . Preliminary morphological analysis of ionospheric effects during solar flares according to the EKB ISTP SB RAS radar data (in russian). In: Plasma physics in solar system-2017, Abstracts. Space Research Institute of RAS; Moscow, Russia: Space Research Institute of RAS; 2017. p. pp.178-178. http://plasma2017.cosmos.ru/files2017/Plasma2017_Abstracts.pdf.

[3] Berngardt O.I. , Zolotukhina N.A. , Oinats A.V. Observations of field-aligned ionospheric irregularities during quiet and disturbed conditions with EKB radar: first results. Earth, Planets and Space 2015;V.67(N.1):pp.143. DOI:10.1186/s40623-015-0302-3.

[4] Bianchi C. , Meloni A. . Natural and man-made terrestrial electromagnetic noise: an outlook. Annals of Geophysics 2007;V.50(N.3):pp.435-445. DOI:10.4401/ag-4425.

[5] Birch M.J., Hargreaves J.K. , Bromage B.J.I. . Properties of auroral radio absorption patches observed in the morning sector using imaging riometer and incoherent-scatter radar. Journal of Atmospheric and Solar-Terrestrial Physics 2013;V.105:pp.262-272. DOI:10.1016/j.jastp.2012.12.004.

[6] Blagoveshchenskii D.V. . Signal absorption effects on HF radio paths near Sodankyla observatory (Finland). Geomagn Aeron 2015;V.55(N.3):pp.316325. DOI:10.1134/s0016793215030032.

[7] Blagoveshchenskii D.V., Maltseva O.A. , Anishin M.M. , Sergeeva M.A. , Rogov D.D. . Impact of the magnetic superstorm on March 17-19, 2015 on subpolar HF radio paths: experiment and modeling. Advances in Space Research 2016;V.58(N.6):pp.835-846. DOI:10.1016/j.asr.2016.05.027. 
[8] Breed A. , Morris R. , Parkinson M. , Duldig M. , Dyson P. . A polar cap absorption event observed using the Southern Hemisphere SuperDARN radar network. In: 34th COSPAR Scientific Assembly. V.34 of COSPAR Meeting; 2002.

[9] Budden K.G. . The Propagation of Radio Waves: The Theory of Radio Waves of Low Power in the Ionosphere and Magnetosphere. Cambridge University Press, 1985. DOI:10.1017/CBO9780511564321.

[10] Carrano C. , Bridgwood C. , Groves K. . Impacts of the December 2006 solar radio bursts on the performance of GPS. Radio Science 2009;V.44(N.1):pp.RS0A25. DOI:10.1029/2008RS004071.

[11] Cerruti A.P., Kintner P.M. , Gary D.E. , Lanzerotti L.J., de Paula E.R. , Vo H.B. . Observed solar radio burst effects on GPS/Wide Area Augmentation System carrier-to-noise ratio. Space Weather 2006;V.4:pp.S10006. DOI:10.1029/2006SW000254.

[12] Chisham G. , Lester M. , Milan S. , Freeman M. , Bristow W. , McWilliams K. , Ruohoniemi J., Yeoman T. , Dyson P. , Greenwald R. , Kikuchi T. , Pinnock M. , Rash J., Sato N., Sofko G. , Villain J.P. , Walker A. . A decade of the Super Dual Auroral Radar Network (SuperDARN): scientific achievements, new techniques and future directions. Surv Geophys 2007;(N.28):pp.33-109. DOI:10.1007/s10712-007-9017-8.

[13] Contreira D.B. , Rodrigues F.S. , Makita K. , Brum C.G.M. , Gonzalez W. , Trivedi N.B. , da Silva M.R. , Schuch N.J. . An experiment to study solar flare effects on radio-communication signals. Advances in Space Research 2005;V.36(N.12):pp.2455 - 2459. DOI:10.1016/j.asr.2004.03.019.

[14] DRAP Documentation . Global D-region absorption prediction documentation. http://www.swpc.noaa.gov/content/global-d-region-absorptionprediction-documentation.

[15] DRAP2 PD Document . Experimental D Region Absorption Prediction, Release 2 (DRAP2) Product Description Document (PDD). http://products.weather.gov/PDD/SWxDRAP2.pdf.

[16] Eccles J.V. , Hunsucker R.D. , Rice D. , Sojka J.J. . Space weather effects on midlatitude HF propagation paths: Observations and a data-driven D region model. Space Weather 2005;V.3(N.1):pp.S01002. DOI:10.1029/2004sw000094.

[17] Gauld J.K. , Yeoman T. , Davies J.A. , Milan S. , Honary F. . SuperDARN radar HF propagation and absorption response to the substorm expansion phase. Annales Geophysicae 2002;V.20:pp.1631-1645. DOI:10.5194/angeo20-1631-2002. 
[18] Greenwald R. , Baker K.B. , Dudeney J.R. , Pinnock M. , Jones T. , Thomas E. , Villain J.P., Cerisier J.C. , Senior C. , Hanuise C. , Hunsucker R.D. , Sofko G. , Koehler J., Nielsen E. , Pellinen R., Walker A. , Sato N. , Yamagishi H. . Darn/Superdarn: A Global View of the Dynamics of High-Lattitude Convection. Space Science Reviews 1995;V.71:pp.761-796. DOI:10.1007/BF00751350.

[19] Hunsucker R. , Hargreaves J. . The High-Latitude Ionosphere and its Effects on Radio Propagation. Cambridge atmospheric and space science series. Cambridge University Press, 2002.

[20] Kainuma S. , Ishii M. , Murayama Y., Kikuchi T. , Mori H. , Igarashi K. . Drift motion of ionospheric arc-like absorption regions observed with a 256-beam imaging riometer in Alaska. Earth, Planets, and Space 2001;V.53:pp.753-760.

[21] Kataoka R. , Nishitani N. , Ebihara Y. , Hosokawa K. , Ogawa T. , Kikuchi T. , Miyoshi Y. . Dynamic variations of a convection flow reversal in the subauroral postmidnight sector as seen by the SuperDARN Hokkaido HF radar. Geophys Res Lett 2007;V.34(N.21):pp.L21105. DOI:10.1029/2007gl031552.

[22] Kikuchi T. , Yamagishi H. . Latitudinal features of cosmic noise absorption at the time of SSC-triggered substorm as observed with scanning beam riometer. Proceedings of the NIPR Symposium on Upper Atmosphere Physics 1989;V.2:pp.9-14.

[23] Little C.G. , Leinbach H. . The Riometer-A Device for the Continuous Measurement of Ionospheric Absorption. Proceedings of the IRE 1959;V.47(N.2):pp.315-320. DOI:10.1109/JRPROC.1959.287299.

[24] Maslin N. . HF Communications: A Systems Approach. CRC Press, 2003.

[25] Milan S. , Jones T. , Lester M. , Warrington E. , Reeves G. . Substorm correlated absorption on a $3200 \mathrm{~km}$ trans-auroral HF propagation path. Annales Geophysicae 1996;V.14:pp.182-190. DOI:10.1007/s00585-996-0182-8.

[26] Ribeiro A.J. , Ruohoniemi J. , Baker J. , Clausen L.B.N. , Greenwald R. , Lester M. . A survey of plasma irregularities as seen by the midlatitude Blackstone SuperDARN radar. J Geophys Res 2012;V.117(N.A2):pp.A02311. DOI:10.1029/2011ja017207.

[27] Rogers N.C. , Kero A., Honary F. , Verronen P.T. , Warrington E.M. , Danskin D.W. . Improving the twilight model for polar cap absorption nowcasts. Space Weather 2016;V.14(N.11):pp.950-972. DOI:10.1002/2016SW001527.

[28] Rogov D.D. , Moskaleva E.V. , Zaalov N.Y. . Modeling of high frequency radio wave absorption on oblique soundings during a solar Xray flare. Advances in Space Research 2015;V.55(N.2):pp.597 - 604. DOI:10.1016/j.asr.2014.11.001. 
[29] Rose D.C. , Ziauddin S. . The polar cap absorption effect. Space Science Reviews 1962;V.1(N.1):pp.115-134. DOI:10.1007/BF00174638.

[30] Sauer H.H., Wilkinson D.C. . Global mapping of ionospheric HF/VHF radio wave absorption due to solar energetic protons. Space Weather 2008;V.6(N.12):pp.S12002. DOI:10.1029/2008SW000399.

[31] editors: Scherer K., Fichtner H., Heber B., Mall U. Space Weather: The Physics Behind a Slogan. Springer, Berlin, 2005.

[32] Squibb C.O., Frissell N.A., Ruohoniemi J.M. , Baker J.B.H. , Fiori R. , Moses M.L. Dayside Ionospheric Response to X-Class Solar Flare Events Observed with Reverse Beacon Network High Frequency Communication Links. In: Virginia Tech REU Symposium - Poster Presentation. Virginia Tech REU Program; Blacksburg, VA: Virginia Tech REU Program; 2015. .

[33] Vertogradov G.G. , Uryadov V.P. , Vertogradova E.G. , Ponyatov A.A. . Ultralong-range sounding of the ionospheric HF channel using an ionosonde/direction finder with chirp modulation of the signal. Radiophysics and Quantum Electronics 2010;V.53(N.3):pp.161-170. DOI:10.1007/s11141-010-9212-1.

[34] Watanabe D. , Nishitani N. . Study of ionospheric disturbances during solar flare events using the SuperDARN Hokkaido radar. Advances in Polar Science 2013;V.24(N.1):pp.12-18. DOI:10.3724/sp.j.1085.2013.00012. 